Australian Journal of

Crop Science

AJCS

AJCS 13(09):1540-1545 (2019)

ISSN:1835-2707

doi: 10.21475/ajcs.19.13.09.p1872

\title{
Genetic parameters and yield potential of polyembryonic maize genotypes
}

\author{
Juan Samuel Guadalupe Jesús Alcalá-Rico ${ }^{1}$, Alfonso López-Benítez ${ }^{1 *}$, Odilon Gayosso-Barragán ${ }^{1}$, Julio Narcizo \\ Ek-Maas ${ }^{1}$, Dreyli Maygualida Hidalgo-Ramos ${ }^{1}$, José Ángel Marroquín-Morales ${ }^{2}$
}

\author{
${ }^{1}$ Departamento de Fitomejoramiento, Universidad Autónoma Agraria Antonio Narro, Calzada Antonio Narro 1923, \\ Buenavista, Saltillo, Coahuila, México. C.P.25315 \\ ${ }^{2}$ Departamento de Riego y Drenaje, Universidad Autónoma Agraria Antonio Narro, Calzada Antonio Narro 1923, \\ Buenavista, Saltillo, Coahuila, México. C.P.25315
}

*Corresponding author: alfopezbe_2000@hotmail.com

\section{Abstract}

In the context of the mutants, polyembryony in maize (PEm) has agronomic potential; therefore, the inclusion of the PEm in new varieties may be useful when considering the ascending demand for food. The objective of this study was to develop new genotypes with high productivity potential, superior to in local area, and useful for family and extensive agriculture. In this work, single crosses were carried out between three pure lines and the high frequency polyembryonic populations. The resulting F1 were advanced to the third generation (G3) and the genotypes obtained from this last generation were used as progenitors of a mating plan, according to the Griffing method 4. The resulting crosses were evaluated in a yield test measuring common characteristics of economic importance (Days to Male Flowering (MF), Plant Height (PH), Cob Height (CH), Fusarium Rotten cobs, Cobs (CFUS), Yield (YLD), and analyzed with the computer routine DIALLEL-SAS05. The results allowed to indicate that both the source of variation Genotypes as additive effects (GCA) presented significance for all variables, while non-additive (SCA) were significant only in the variables of cob sanity ( $p \leq 0.01$ ) and productivity $(p \leq 0.05)$. In this regard, most of the variables showed a greater contribution of the effects of General Combining Ability (GCA) compared to Specific Combining Ability (SCA). In addition, it was observed that the crosses were superior in all the variables evaluated with respect to BAP and NAP, and statistically similar in some cases with respect to hybrids. This means that this type of segregant polyembryony crosses can compete with other materials evaluated in the region. The estimation of GCA and SCA generated information on the potential of the studied parents and their crosses and are worthy of being taken into account in the formation of varieties.

Keywords: Diallelic, Polyembryony, Yield test, Zea mays.

Abbreviations: GCA_General combining ability; SCA_Specific combining ability; PEm_Polyembryony in maize; AP+_positive preferential mating.

\section{Introduction}

The knowledge of genetic variation of a population of interest, is indispensable in the breeding programs of any cultivated species, in this case, maize. The mutation produces phenotypic differences between individuals that is essential to allow plants to adapt to a physical and biological environment in continuous change, which can be used in breeding programs (Nogué et al., 2016).

In studies on mutants in maize, either for applications in genetic improvement or for studies of domestication, or in recent topics related to genomics, there is a record of a large number of characteristics or treatments of economic importance. Polyembryony in maize (PEm) is the condition where the germinating seed manifests two or more plumules simultaneously, which are maintained until the end of life cycle of the plant (Webber, 1940).

Espinoza et al. (1998) reported that the base germplasm was observed in the Instituto Mexicano del Maíz of the Universidad Autónoma Agraria Antonio Narro (IMM-UAAAN). The mixture of seeds extracted from twin plants, which had a frequency of less than $1.5 \%$ of a group of related progenies of the "square stem" type, whose characteristic was given by two identical and intimately linked plants. The next generation of the base population presented normal, twin and square stem plants. From 1992, the germplasmic base of the PEm, was divided into two groups: one for dwarf size (BAP) and another for normal size (NAP), with a reproductive management within each group of fraternal crosses with pollen mixture. 
The inheritance of the polyembryonic character in corn is controlled by two duplicated recessive epistatic loci, where the normal condition of the plant is presented with only the presence of a dominant allele. This condition can also present incomplete penetrance of up to $50 \%$, which means that the PEm is not phenotypically expressed in all the screens (Rebolloza et al., 2011).

Crosses between populations of high polyembryony (NAP and BAP) by exotic material of different origin, regularly produce $F_{1}$ phenotypic normal progenies, which indicates the "recessive" nature of the PEm, and the dominant "normal" condition the exotic sources. The recovery of the PEm can be obtained from generation $F_{2}$ (crosses plant to plant, within each segregating group), or the $\mathrm{RC}_{1}$ of $\mathrm{F}_{1} \times \mathrm{NAP}$ or $\mathrm{BAP}$, which present progenies that manifest the PEm in proportions of $15: 1$ and 12:4, respectively (González et al., 2011).

Different methods have been proposed for the analysis of mating designs for the purpose of genetic studies. Sprague and Tatum (1942) proposed the method that includes the diallel crosses and that originated the concepts of General Combining Ability (GCA) and Specific Combining Ability (SCA). In the genetic mating systems called diallel, all possible crosses between several genotypes are carried out (Hayman, 1954; Kempthorne, 1956). This has been successfully applied by plant breeders, both in the use of lines and populations, with the purpose to estimate effects of GCA and SCA, reciprocal effects $(\mathrm{RE})$, components of variance, levels of heterosis and heritability (Griffing, 1956; Gardner and Eberhart, 1966).

The knowledge of the combinatorial effects of parents are essential, through which breeder obtains information on the gene action in quantitative characters of agricultural importance. This allows establishing improvement schemes to select genotypes with good average behavior in a series of crosses and to identify combinations specific hybrids in the selection of superior genotypes (Gardner and Eberhart, 1966; Ávila et al., 2009). In this work, the following objectives were proposed: (1) to test the agronomic-productive capacities of combinations of different germplasm sources that include polyembryony and (2) to obtain the genetic parameters of General Combining Ability (GCA) and Specific Combining Ability (SCA).

\section{Results and discussion}

\section{Components of the genetic variance of diallel cross by Griffing method 4}

The effects of combining ability for six variables of interest are presented in Table 2. In this research, we found that both genotypes and additive effects had significance $(p \leq 0.01)$ for all variables except CFUS that showed significant differences $(p \leq 0.05)$ in the GCA variation source, while non-additive effects showed high significance $(p \leq 0.01)$ for the variables $R C$, CFUS and differences $(p \leq 0.05)$ for YLD. This means that genotypes have a different capacity to transmit their characteristics to the offspring and present a different performance in specific hybrid combinations. Therefore, it is possible to detect the best segregating genotypes of the PEm, and those crosses that show the best SCA values for the possible formation of varieties or hybrids.

Regarding the components of genetic variance, it is observed that for all the studied variables the additive variance was manifested to a greater degree than the variance of dominance with the exception of $\mathrm{PH}$ and CFUS, which could have influenced the heritabilities, presenting values from intermediate to high. The predominance of additive variance may favor the improvement of selection efficiency in segregating populations (Bocanski et al., 2009).

\section{Contribution of the variance of additive and non-additive effects}

Table 3 shows the estimation of the contribution ratio of the effects of GCA and SCA according to the sum of squares of the analysis of variance of Griffing method 4. The variables MF, HP, $\mathrm{HC}, \mathrm{RC}$ and YLD presented higher values in the effects of GCA, which indicates that the additive gene action was involved in these variables in a prevalent manner. These results agree with what was said by Moll and Robinson (1967) who pointed out that the additive genetic variance is at least twice as large as the variance of dominance in maize populations. On the other hand, Beyene et al. (2017) mentioned that the action of the additive gene is more important than the action of the nonadditive gene when the effects of GCA are greater than the effects of SCA. In addition, its importance lies in the fact that its characteristics are inherited from the parents for its progeny, determinants of the genetic properties of the population and the response to selection (Silva et al., 2018).

\section{General Combining Ability (GCA)}

The punctual data of General Combining Ability are presented in Table 4, where it can be observed that the segregating genotypes $B$ and $E$ stand out according to the agronomic characteristics of interest, contributing precocity in the MF variable, and reducing the RC in addition to increasing the HP. In the yield variable, genotype $B$ and $E$ contributed $1.96 \mathrm{t}$ and $0.6 \mathrm{t}$ above the mean, respectvely. This is reflected in most of the crosses where these genotypes are involved, surpassing the general average, which means that the genotypes have a different capacity to transmit their characteristics to offspring. The segregating genotypes $A$ and $C$ have significant negative effects in HP, HC and YLD, which can influence any other genotype after crossing. This reduces the height and obtain lower yield values as mentioned by Márquez (1998), who reported that genetic value of the lines determine the degree of behavior that the crosses will present.

\section{Specific Combining Ability (SCA)}

The effects of SCA for six variables are presented in Table 5. The crosses BA and CE were considered as the best hybrid combinations since they contributed greater precocity, presenting negative values in $\mathrm{MF}$, low bearing in $\mathrm{HP}$, reduction of RC. This favored $1.01 \mathrm{t} \mathrm{ha}^{-1}$ to YLD, which is probably due to genetic differences between the exotic genotypes and their 
Table 1. Genotypes used in this field experiments.

\begin{tabular}{llllll}
\hline \multicolumn{2}{l}{ Inbred lines } & & \multirow{2}{*}{ Pol. } & \multicolumn{2}{l}{ Initial crosses } \\
\cline { 1 - 2 } \cline { 5 - 6 } Lines & Pedigree & Origin & & Cross \\
\hline 1 & G32-C19-HS32-1-\#-2-B-\#*3-3-B & CIMMYT & NAP & A & NAP $\times$ CML-78 \\
2 & AN-7 & UAAAN & BAP & B & NAP $\times$ AN-7 \\
3 & AN-255-18-19 & UAAAN & & C & BAP $\times$ CML-78 \\
& & & & E & NAP $\times$ AN-255-18-19 \\
\hline
\end{tabular}

Table 2. Mean squares of the analysis of variance of a diallel under Griffing method 4 for six crosses.

\begin{tabular}{|c|c|c|c|c|c|c|c|c|c|c|c|c|c|}
\hline SV & DF & $\mathrm{MF}$ & & $\mathrm{HP}$ & & $\mathrm{HC}$ & & $\mathrm{RC}^{\ddagger}$ & & CFUS $^{\ddagger}$ & & YLD & \\
\hline REP & 2 & 5.06 & & 14.9 & & 46.77 & & 0.97 & & 13.94 & & 0.26 & \\
\hline GEN & 5 & 10.32 & $* *$ & 1267.52 & $* *$ & 439.23 & $* *$ & 290.47 & $* *$ & 92.8 & $* *$ & 10.84 & $* *$ \\
\hline GCA & 3 & 16.72 & $* *$ & 2051.41 & $* *$ & 729.65 & $* *$ & 362.29 & $* *$ & 42.82 & $*$ & 14.92 & $* *$ \\
\hline SCA & 2 & 0.72 & & 91.69 & & 3.6 & & 182.76 & $* *$ & 167.77 & $* *$ & 4.73 & $*$ \\
\hline ERROR & 10 & 1.26 & & 33.78 & & 26.94 & & 10.5 & & 6.22 & & 1.27 & \\
\hline $\mathrm{CV}$ & & 1.41 & & 2.89 & & 4.57 & & 17.13 & & 9.88 & & 8.98 & \\
\hline $\mathrm{R}^{2}$ & & 83 & & 95 & & 89 & & 93 & & 89 & & 81 & \\
\hline MEAN & & 79.4 & & 201.2 & & 113.7 & & 12.5 & & 18.8 & & 12.5 & \\
\hline$\sigma \mathrm{A}$ & & 4.59 & & 653.24 & & 242.02 & & 82.31 & & -67.48 & & 3.40 & \\
\hline$\sigma D$ & & -0.18 & & 653.24 & & -7.78 & & 78.48 & & 93.88 & & 1.15 & \\
\hline$h^{2}$ & & 0.95 & & 0.50 & & 1.00 & & 0.50 & & -2.26 & & 0.68 & \\
\hline
\end{tabular}

Yield, $\neq$ Variable data with Arco-Seno transformation.

Table 3. Percentage of contribution of additive and non-additive effects for six variables.

\begin{tabular}{lllllll}
\hline EFFECT & MF & HP & HC & RC & CFUS & YLD \\
\hline GCA & 97.2 & 97.1 & 99.7 & 74.8 & 31.5 & 82.6 \\
SCA & 2.8 & 2.9 & 0.3 & 25.2 & 68.5 & 17.4 \\
\hline MF: Male flowering, PH: Plant height, HC: Cob height, RC: Rotten cobs, CFUS: Fusarium cobs, YLD: Yield.
\end{tabular}

Table 4. General Combinatorial Ability (GCA) of four segregant genotypes of polyembryony, estimated under Griffing method 4.

\begin{tabular}{|c|c|c|c|c|c|c|c|c|c|c|c|c|}
\hline GEN & $\mathrm{MF}$ & & $\mathrm{HP}$ & & $\mathrm{HC}$ & & $\mathrm{RC}$ & & CFUS & & YLD & \\
\hline$B$ & 0.58 & & 25.27 & $* *$ & 15.10 & $* *$ & -11.46 & $* *$ & 4.73 & $* *$ & 1.96 & $* *$ \\
\hline A & 0.42 & & -14.60 & $* *$ & -7.48 & $* *$ & 9.09 & $* *$ & 0.45 & & -1.27 & $* *$ \\
\hline C & 1.42 & $*$ & -12.98 & $* *$ & -8.90 & $* *$ & -2.79 & $*$ & -4.65 & $* *$ & -1.29 & $* *$ \\
\hline$E$ & -2.42 & $* *$ & 2.31 & & 1.27 & & 5.16 & $* *$ & -0.54 & & 0.60 & \\
\hline
\end{tabular}

Table 5. Specific combining ability (SCA) of six crosses obtained from crossing between four segregant genotypes of polyembryony, estimated under Griffing method 4.

\begin{tabular}{|c|c|c|c|c|c|c|c|c|c|c|}
\hline CROSSES & MF & $\mathrm{HP}$ & & $\mathrm{HC}$ & $\mathrm{RC}$ & & CFUS & & YLD & \\
\hline $\mathrm{BA}$ & -0.39 & -2.24 & & 0.36 & -7.28 & $* *$ & 6.56 & $* *$ & 1.01 & $*$ \\
\hline BC & 0.28 & -2.28 & & 0.53 & 5.00 & $* *$ & -7.34 & $* *$ & -0.64 & \\
\hline$B E$ & 0.11 & 4.51 & $*$ & -0.89 & 2.28 & & 0.78 & & -0.38 & \\
\hline$A C$ & 0.11 & 4.51 & $*$ & -0.89 & 2.28 & & 0.78 & & -0.38 & \\
\hline $\mathrm{AE}$ & 0.28 & -2.28 & & 0.53 & 5.00 & $* *$ & -7.34 & $* *$ & -0.64 & \\
\hline $\mathrm{CE}$ & -0.39 & -2.24 & & 0.36 & -7.28 & $* *$ & 6.56 & $* *$ & 1.01 & $*$ \\
\hline
\end{tabular}

Table 6. Mean squares of the analysis of variance in the six genotypes resulting from diallel crosses and four controls.

\begin{tabular}{|c|c|c|c|c|c|c|c|c|c|c|c|c|c|}
\hline SV & $\mathrm{DF}$ & $\mathrm{MF}$ & & $\mathrm{HP}$ & & $\mathrm{HC}$ & & $\mathrm{RC}^{\ddagger}$ & & CFUS ${ }^{\ddagger}$ & & YLD & \\
\hline GEN & 9 & 18.95 & $* *$ & 1300.57 & $* *$ & 611.45 & $* *$ & 326.93 & $* *$ & 202.95 & $* *$ & 24.63 & $* *$ \\
\hline REP & 2 & 3.33 & & 10.78 & & 3.92 & & 0.67 & & 14.10 & & 2.06 & \\
\hline Error & 18 & 1.37 & & 37.56 & & 43.59 & & 9.98 & & 6.89 & & 2.19 & \\
\hline $\mathrm{CV}$ & & 1.48 & & 3.05 & & 5.93 & & 16.92 & & 11.99 & & 11.45 & \\
\hline $\mathrm{R}^{2}$ & & 88 & & 95 & & 88 & & 94 & & 94 & & 85 & \\
\hline MEAN & & 79.1 & & 200.7 & & 111.4 & & 12.7 & & 15.4 & & 12.9 & \\
\hline
\end{tabular}

$*, * *$ Significant at the probability levels $\leq 0.05$ and $\leq 0.0 .1$
Yield, $\neq$ Variable data with Arco-Seno transformation. 
Table 7. Comparison of Tukey means $(\alpha=0.05)$, of the six genotypes resulting from diallel crosses and four controls.

\begin{tabular}{|c|c|c|c|c|c|c|c|c|c|c|c|c|}
\hline GEN & MF & & $\mathrm{HP}$ & & $\mathrm{HC}$ & & $\mathrm{RC}$ & & CFUS & & YLD & \\
\hline$\overline{A C}$ & 81.3 & $a b$ & 178.2 & de & 96.4 & c & 21.1 & $b$ & 15.4 & $\mathrm{~cd}$ & 9.6 & $\mathrm{e}$ \\
\hline$A E$ & 77.7 & $\mathrm{~cd}$ & 186.7 & $d$ & 108 & bc & 31.7 & $a$ & 11.3 & de & 11.2 & cde \\
\hline BA & 80 & $a b c$ & 209.7 & $b$ & 121.7 & $a b$ & 2.8 & c & 30.5 & a & 14.3 & abcd \\
\hline$B C$ & 81.7 & $a$ & 211.3 & $b$ & 120.4 & $a b$ & 3.2 & c & 11.5 & de & 12.6 & bcde \\
\hline $\mathrm{BE}$ & 77.7 & $\mathrm{~cd}$ & 233.3 & $a$ & 129.2 & $a$ & 8.5 & c & 23.7 & $a b$ & 14.7 & $a b c$ \\
\hline CE & 78 & $\mathrm{bcd}$ & 188.3 & $\mathrm{~cd}$ & 106.4 & $b c$ & 7.6 & c & 20.1 & bc & 12.9 & bcde \\
\hline NAP & 81.7 & $a$ & 220 & $a b$ & 134.2 & $a$ & 27.7 & $a b$ & 14.2 & $\mathrm{~cd}$ & 10.1 & de \\
\hline BAP & 81.7 & $a$ & 164.5 & e & 90.8 & c & 20.3 & $b$ & 21.1 & $b c$ & 9.6 & e \\
\hline CAI & 75.7 & $d$ & 210 & $b$ & 103.3 & $b c$ & 2.7 & c & 4.8 & ef & 17.6 & $a$ \\
\hline HER & 75.3 & $d$ & 205 & $b c$ & 103.3 & $b c$ & 1.4 & C & 1.4 & $\mathrm{f}$ & 16.8 & $b$ \\
\hline
\end{tabular}

cross-breeding counterparts, the polyembryonic populations. Also, in those crosses of good SCA, it is observed that at least one of the progenitors presented high GCA. These results confirmed De la Cruz et al. (2003), who found that the highest yield crosses were formed by lines of different origin and genetically different.

Although the $B E$ crosses had a negative but not significant value in the YLD variable, the contribution of the additive effects that these two genotypes present were favorably expressed in the yield. These results agree with Sánchez et al. (2017) and Escorcia et al. (2010) who mentioned that a single cross has high yield when the two progenitor lines present a high GCA, or that at least one line has high GCA and positive effects of SCA.

\section{Valuation of the potential of diallel crosses}

The diallel crosses were evaluated including reference populations to polyembryony and two hybrids, where the data obtained were subjected to analysis of variance to confirm the potential between the different genotypes in each of the variables involved. The results of the analysis of variance are shown in Table 6 . It can be seen that the genotypes showed significance $(p \leq 0.01)$ for all the variables. This indicates that the genotypes behave differently with respect to each variable and; therefore, at least one must be better than the rest in each group within a variable. The fact above can be verified by observing Tukey's mean comparison ( $p \leq 0.05$ ) (Table 7). In general, the genotypes that showed a high HP concomitantly exhibited higher HC and high YLD. These agronomic characteristics are of great importance in the selection of the corn crop architecture (Li et al., 2017). These are indispensable in the increase of population density to maximize the use of fertilizer, humidity and incident photosynthetic radiation (Rao et al., 2014; Mock and Pearce, 1975). However, there is a high negative association between RC and YLD, so the first affects the second, reducing cob production. These data coincide with Mu et al. (2018) who mentioned that it is one of the most important maize diseases, which can severely reduce grain yield and quality. According to the desired agronomic characteristics (precocity, average size, good sanity, good yield) the diallel crosses showed superiority in all the variables evaluated when compared with the BAP and NAP populations, which are the reference to the PEm. In addition, they were statistically the same in some cases with respect to hybrid high-yield controls. In these comparisons, BA and BE were detected as the best diallel crosses. This allows us to mention that the evaluation of GCA and SCA by diallel crossings was efficient in the classification of progenitors that could be useful to generate genotypes, hybrids and varieties with desirable characteristics in the improvement of crops (Rathore and Chauhan, 2017).

\section{Materials and methods}

\section{Genetic material}

At the beginning of the experiment, a series of crosses was carried out between pure lines with proven combinatorial aptitude (called as exotic material, due to its nonpolyembryonic condition) and the polyembryonic high frequency populations generated in IMM-UAAAN (They named NAP by its normal size and BAP for having a dwarf size (Espinoza et al., 1998) (Table 1). The $F_{1}$ generated, were taken to $F_{2}$ through plant-to-plant crosses (carnal brothers, or complete) within each group. The reproductive management of PEm plants from $\mathrm{F}_{2}$ was through positive preferential mating $(\mathrm{AP}+)$ within each group, based on the polyembryonic condition. This means that only double plants were mated to rise to the third (G3) and in this way maintain the same germplasm composition (exotic $\times$ NAP, or $\times$ BAP, in 50:50 dose). This was thought so, considering that the exotic sources in combination with the source populations of polyembryony, would contribute to improve the agronomic characteristics of the genotypic groups resulting from these processes.

\section{Establishment of experiments}

The present investigation was carried out in a series of experiments.

The first experimental works, where three segregant generations of the PEm (F1, F2, G3) of the groups under study obtained, were carried out in the facilities of Universidad Autónoma Agraria Antonio Narro (UAAAN), in Buenavista, Saltillo, Coahuila, Mexico, located at coordinates $25^{\circ} 22^{\prime} \mathrm{N}$, $101^{\circ} 02^{\prime} \mathrm{W}$ and altitude of 1742 masl, presenting characteristics of dry, semi-warm climate, with average annual precipitation of $350-400 \mathrm{~mm}$, average annual temperature of 
$19.8^{\circ} \mathrm{C}$ and clay loam texture soil with low contents of organic matter. The field experiments were carried out in two locations, the first in the experimental field of Instituto Nacional de Investigaciones, Forestales Agrícolas y Pecuarias (INIFAP) -Río Bravo, Tamaulipas with coordinates: $25^{\circ} 57^{\prime} \mathrm{N}$, $98^{\circ} 01^{\prime} \mathrm{O}$ and altitude of 25 masl, whose climate is semi-arid subtropical warm, annual average precipitation of $653 \mathrm{~mm}$, average annual temperature of $22.6^{\circ} \mathrm{C}$ and vertisol soil with clay texture. In this site, the experimental work consisted of developing a series of diallel crosses from four segregant genotypes of the polyembryony character which were in the third generation (G3), using the mating plan corresponding to Griffing method 4 (1956). This is because in this generation the genotypes had sufficient frequency of the character of the polyembryony to be able to make the crosses through AP+ and thus maintain the character. The second locality is located in the Buenavista Experimental Field, in the facilities of the UAAAN, in which a yield test of some of the crosses resulting from the diallel was carried out.

\section{Variables evaluated}

Days to male flowering (MF): Days passed from sowing to the development of $50 \%$ of dehiscent anthers; Plant height (PH): distance in centimeters from the base of the stem to the flag leaf; Cob height $(\mathrm{CH})$ : This length $(\mathrm{cm})$ was determined from the base of the plant to the node where the main cob emerges; Rotten cobs (RC): Percentage of cobs with damage caused by different species of fungi with respect to the total cobs of corn harvested; Cobs with Fusarium (CFUS): Percentage of cobs that show damage by this pathogen, in relation to the total of cobs harvested; Yield (YLD): Is the estimated production per experimental plot reported in $t \mathrm{ha}^{-1}$ of cobs at $15.5 \%$ humidity

\section{Analysis of data}

The diallel designs were analyzed with the computational routine DIALLEL-SAS05, proposed by Zhang et al. (2005).

The yield trial data were analyzed through the analysis of variance according to the design used. In the cases where there were statistical differences, a Tukey multiple range means test was performed, $\mathrm{p} \leq 0.05$.

\section{Conclusion}

The agronomic behavior of the segregating genotypes of polyembryony showed positive intermediate values when compared with the controls, who presented the extreme values, corresponding to the population of high polyembryony (the least qualified) and the commercial hybrid CAI (the most qualified), respectively. The estimation of General Combining Ability and Specific Combining Ability generated information about the potential of the four parents studied and their crosses, presenting superiority of additive effects, where $B$ and $E$ were the best genotypes, and $B A, B E$ and $C E$ turned out to be the best most outstanding crosses.

\section{Acknowledgments}

We would like to thank the Instituto Mexicano del Maíz (IMM) of the Universidad Autónoma Agraria Antonio Narro (UAAAN) for providing the genetic materials and the Consejo Nacional de Ciencia y Tecnología (CONACYT) for the scholarship for graduate studies awarded to the main author.

\section{References}

Ávila PM, Rodríguez HS, Vázquez BM, Borrego EF, Lozano RA and López BA (2009) Combinig ability and reciprocal effects in maize inbred lines from the highlands of central México. Agric Téc Méx. 35(3): 285-293.

Beyene Y, Gowda M, Suresh LM, Mugo S, Olsen M, Oikeh S O, Juma C, Tarekegne A and Prasanna BM (2017) Genetic analysis of tropical maize inbred lines for resistance to maize lethal necrosis disease. Euphytica. 213(9), 224.

Bocanski J, Sreckov Z, and Nastasic A (2009) Genetic and phenotypic relationship between grain yield and components of grain yield of maize (Zea mays L.). Genetika. 41(2): 145-154.

De La Cruz LE, Ron J, Ramírez J, Sánchez J, Morales M, Chuela M, Hurtado S and Mena, S (2003) Heterosis and combining ability among commercial hybrids and exotic maize germplasm in Jalisco, México. Rev Fitotec Mex. 26(1):1-10.

Escorcia GN, Molina GJD, Castillo GF and Mejía CJA (2010) Yield, heterosis and inbreeding depression of single crosses of maize. Rev Fitotec Mex. 33 (3): 271-279.

Espinoza J, Vega MC, Navarro E and Burciaga GA (1998) Poliembrionía en maíces de porte normal y enano. Agron Mesoam. 9(2):83-88.

Gardner CO and Eberhart SA (1966) Analysis and interpretation of the variety cross diallel and related populations. Biometrics. 22(3):439-452.

González VVM, Espinoza VJ, Mendoza VR, De León CH and Torres TMA (2011) Characterisation of maize germoplasm that combines a high oil content and polyembryony. Universidad y Ciencia. 27(2):157-167.

Griffing B (1956) Concept of general and specific combining ability in relation to diallel crossing systems. Aust J Biol Sci. 9(4):463-493.

Hayman BI (1954) The theory and analysis of diallel crosses. Genetics. 39(6):789-809.

Kempthorne $O$ (1956) The theory of diallel cross. Genetics. 41(4):451-459.

Li H, Yang Q, Fan N, Zhang M, Zhai H, Ni Z, and Zhang Y (2017) Quantitative trait locus analysis of heterosis for plant height and ear height in an elite maize hybrid zhengdan 958 by design III. BMC genet. 18(1), 36.

Márquez SF (1988) Genotecnia vegetal. Métodos, teoría y resultados. Tomo II. AGT editor, México. $665 \mathrm{p}$.

Mock JJ and Pearce RB (1975) An ideotype of maize. Euphytica. 24(3), 613-623.

Moll RH and Robinson HF (1967) Quantitative genetics investigations of yield of maize. Genet Breed Res. 37(4):192205. 
Mu C, Gao J, Zhou Z, Wang Z, Sun X, Zhang X, Dong H, Han Y, Li $X$, Wu Y, Yunxia $C$, Ma $P$, Dong $C$, Chen J and $W u J$ (2018). Genetic analysis of cob resistance to $F$. verticillioides: another step towards the protection of maize from ear rot. Theor Appl Genet. 1-11.

Nogué F, Mara K, Collonnier C, and Casacuberta JM (2016) Genome engineering and plant breeding: impact on trait discovery and development. Plant cell reports. 35(7), 14751486.

Rathore RKS, and Chauhan Y (2017) GCA and SCA effects analysis for grain yield and its quantitative traits in six-rowed barley (Hordeum vulgare L.) in Agra region. Int J Sci Res. 5664.

Rao P, Subbaiah G, and Veeraraghavaiah R (2014) Agronomic responses of maize to plant population and nitrogen availability-a review. Int J PI An and Env Sci. 4, 107-16.
Rebolloza HH, Espinoza VJ, Sámano GD, Zamora VVM (2011) Polyembryony inheritance in two experimental maize populations. Rev Fitotec Mex. 34(1), 27-33.

Sánchez RFJ, Mendoza CMD, Mendoza RM, Castillo GF, Cruz IS, Castro NS and Molina GJD (2017) Combining ability of inbred lines for maize (Zea mays L.) single cross hybrid production under irrigation. Agrociencia. 51(4):393-407.

Silva DR, García MP, Faleiro SD and Souza CL (2018) Estimation of variance components and genetics parameters in a segregating population of tropical maize. Bioagro. 30 (1): $67-$ 77.

Sprague GS and Tatum LA (1942) General vs specific combining ability in single crosses of corn. J Amer Soc Agron. 34:923932.

Webber JM (1940) Polyembryony. Bot Rev. 6(11):575-598.

Zhang Y, MS Kang and KR Lamkey (2005) Diallel-SAS05: A comprehensive program for Griffing's and Gardner-Eberhart analyses. Agron J. 97:1097-1106. 